\title{
The Effect of Experimental Maternal Hypoxia on Fetal Lung Growth
}

\author{
JANET E. LARSON AND WILLIAM M. THURLBECK \\ Department of Pathology, University of British Columbia and the Department of Pathology, British Columbia's \\ Children's Hospital, Vancouver, British Columbia, Canada
}

\begin{abstract}
Timed-pregnant rats at a gestational age of 14 days were exposed to $10 \%$ ambient oxygen (normobaric hypoxia) and compared to pair-fed animals of the same gestation and controls fed ad libitum. The lungs of the offspring were analyzed morphometrically and biochemically at day 21 of gestation after cesarean section. The hypoxic mothers and the pair-fed mothers showed similar diminution of weight gain and their fetuses showed growth retardation, more so in those of the hypoxic mothers. The lung volumes and weights were significantly different in the offspring of hypoxic and pair-fed mothers compared to those of mothers fed ad libitum. However, the lung volume and lung weight to body weight ratios were not different between groups, including pair-fed and hypoxic, and lung size was proportional to the amount of general growth segment in all. Morphometric analysis showed the volume proportion of saccular air, saccular wall, conducting airways, and nonparenchyma to be the same in each group. The gas exchanging surface areas were also the same. Dry lung weight, DNA, and protein per lung were decreased in the offspring of hypoxic mothers compared to the two other groups. The issue of whether the offspring of the hypoxic mothers should be regarded as having specific hypoplasia because of diminished cell number is discussed. (Pediatr Res 24: 156-159, 1988)
\end{abstract}

Exposure of the developing fetus to chronic hypoxemia by various means has been shown to cause intrauterine growth retardation (1-8). Although these studies have examined aspects of brain, liver, and placental growth, detailed studies of the effect of hypoxia on intrauterine lung growth have not been done. Therefore, we undertook the biochemical and morphometric analysis of fetal lung growth in pregnant rats exposed to chronic hypoxia.

\section{MATERIALS AND METHODS}

Experimentation. Sprague-Dawley timed-pregnant rats (Charles River Breeding Laboratories, Inc., Wilmington, MA) were made hypoxic from 14-21 days of gestation and compared to a pair-fed group and to a control group fed ad libitum in room air.

The animals were kept in separate cages in exposure chambers. Normobaric hypoxia was induced in the hypoxic group by exposing them to a $10 \%$ ambient oxygen mixture achieved by

Received August 5, 1987; accepted March 18, 1988.

Correspondence and reprint requests William M. Thurlbeck, M.B., Department of Pathology, University of British Columbia, 2211 Westbrook Mall, Vancouver, B.C. V6T IW5, Canada.

Supported by Grant MT 7124 from the Medical Research Council of Canada. J.E.L. is a Fellow of the Medical Research Council of Canada. mixing compressed air and nitrogen. Both the control and pairfed groups received compressed air at 4 liter $/ \mathrm{min}$. The oxygen concentration was measured continuously with a polargraphic oxygen monitor placed within the chambers (Hudson Centronics, Temecula, CA). Carbon dioxide levels were measured daily with a Fryaite Carbon Dioxide Analyzer (Bacharach Instrument Co., Pittsburg, PA) in all chambers and were undetectable. The chambers were cleared of excess humidity by calcium sulfate (W. A. Hammond Drierite Co., Zenia, $\mathrm{OH}$ ) placed in open dishes within the chambers. An equal light/dark exposure cycle of $12 \mathrm{~h}$ was maintained in all of the chambers. The chambers were opened $1 / 2 \mathrm{~h}$ daily for weighing, feeding, and cleaning. The animals in the pair-fed group were timed-pregnant 1 day after the hypoxic group and were weight matched as closely as possible to the hypoxic mothers. They were fed on a per $\mathrm{kg}$ basis the amount of food that the hypoxic mothers had eaten the day before.

At day 21 of gestation, the mothers were sedated with $25 \mathrm{mg} /$ $\mathrm{kg}$ of intraperitoneal pentobarbitol and cesarean section was performed (normal term of gestation 22 days). The fetuses were weighed and taken alternately from both horns for biochemical and morphometric analysis.

Morphometry. The lungs of the fetuses to be used for morphometric analysis were excised and fixed intratracheally with Karnofsky's solution (9) at a pressure of $25 \mathrm{~cm} \mathrm{H}_{2} \mathrm{O}$ for $24 \mathrm{~h}$. The fixed lung volumes were measured by water displacement (10). The left lung was imbedded in Spurr and five consecutive midsagittal sections of $0.75-\mu$ thickness were taken for point counting and determination of mean linear intercept. A standard grid with 42 points per field was used to count the volume proportion of saccules, saccular wall, conducting airways, and nonair-exchanging parenchyma. Mean linear intercept, the distance between airexchanging surfaces, was determined by the number of intercepts of saccular wall across a line of known length. The potential airexchanging surface area of each lung could then be determined (11). One hundred fields were counted on each lung; the experimental groups were blinded to the observer. Lungs were not included in the study if $25 \mathrm{~cm}$ of water pressure was not maintained during inflation, or if the lungs appeared to be improperly inflated either grossly or on microscopic examination.

Biochemistry. In those fetuses used for biochemistry, the lungs were carefully dissected and frozen immediately at $-70^{\circ} \mathrm{C}$. Both the wet and the dry lung weights were measured after lyophilization to constant weight. Lungs of the fetuses from each litter were pooled for analysis. DNA was extracted by the SchmidtThannhauser (12) method with modification (13) and measured by the diphenylamine reaction (14) at a wavelength of $600 \mathrm{~nm}$. Protein was determined by the method of Lowry et al. (15) at a wavelength of $660 \mathrm{~nm}$. Both the absolute and relative amounts of DNA and protein were determined.

Statistical analysis. Statistical comparison of the three groups was done by one-way analysis of variance and the significance between groups was measured by the Tukey's test for multiple 
comparison (16). A probability value of less than 0.05 was considered significant. All data are expressed as mean \pm SEM.

\section{RESULTS}

A total of 18 litters was compared (six mothers in each of the three groups). Maternal weight gains during the period of exposure (days 14-21) were recorded and compared. Whereas the weight of the mothers in the control group increased by $27 \%$ (from a mean of 239.2 to $304.2 \mathrm{~g}$ ) the hypoxic and pair-fed mothers had a $0 \%(250.8$ to $250.5 \mathrm{~g})$ and $4 \%(255.3$ to $266.1 \mathrm{~g})$ weight gain respectively. This weight difference was significant between the control and the two experimental groups, but not different between the hypoxic and pair-fed groups. Food intake of the hypoxic and pair-fed mothers was $48 \%$ of the control mothers.

The mean litter size was $10.5,10$, and 12.1 in the control, hypoxic, and pair-fed groups, respectively. There was no evidence of fetal resorption or gross fetal abnormality except for growth retardation in both experimental groups. Heart beat and spontaneous movement were present in all fetuses.

Table 1 summarizes the fetal weights, lung weights, lung volumes, and specific lung weights and volumes (lung weight and volume to body weight ratios). There was a significant difference in the body weights of the fetuses between each of the three experimental groups. The lung weights were also significantly different between each of the three groups. Specific lung weight was not significantly different between the three groups ( $p=0.6182$ ). The lung volumes of the hypoxic and pair-fed groups were significantly different from the control group, but not from each other. Specific lung volumes were not different between groups.

Biochemical analysis showed the amount of DNA/lung and protein/lung to be significantly lower in the hypoxic animals than both the control and the pair-fed group (see Table 2). There was no difference in the relative amounts of DNA and protein (expressed as per mg dry lung weight) between groups.

Morphologically, all lungs appeared to be in the saccular phase of development (17) which is normally found in the rat at birth (18), and no subjective difference could be found between the groups. Morphometrically, the volume proportions of saccular air, saccular wall, conducting air, and nonparenchyma were not different between the groups (see Fig. 1). There was no difference in the mean linear intercept between the three groups (see Table 3 ). The mean gas-exchanging surface area of the lungs of the hypoxic fetuses was $82 \%$ of the control lungs, whereas the pairfed animals had $97 \%$ of the gas-exchanging surface area of the control lungs. The surface area of the lung was proportional to the weight of each fetus (see Fig. 2). There was no difference in the surface area to volume ratio of airspaces between groups.

\section{DISCUSSION}

Experimental intrauterine growth retardation has been caused by various methods of induction of hypoxemia. Methods previously used include exposing pregnant mothers to decreased ambient oxygen, hypobaria, and ligation of uterine arteries (1-6). Only one of these studies added a pair-fed group after noting that hypoxic animals eat less; this may affect growth parameters (5). The pattern of poor weight gair. was the same in the hypoxic and pair-fed mothers. Thus, we have concluded that the effect of hypoxia on the mothers' weights was mediated through inanition.

There were, however, differences between the hypoxic and pair-fed fetal groups and the growth retardation of the hypoxic fetuses could not be entirely explained by maternal inanition. The lung and body weights of the hypoxic fetuses were significantly lower than those of the control and pair-fed fetuses. We

Table 2. DNA and protein analysis of lung (mean \pm SEM)

\begin{tabular}{lccc}
\hline & $\begin{array}{c}\text { Control } \\
(n)\end{array}$ & $\begin{array}{c}\text { Hypoxic } \\
(n)\end{array}$ & $\begin{array}{c}\text { Pair-fed } \\
(n)\end{array}$ \\
\hline DNA $(\mu \mathrm{g} / \mathrm{lung})$ & $458 \pm 31$ & $328 \pm 30^{*}$ & $437 \pm 22$ \\
& $(6)$ & $(6)$ & $(6)$ \\
Protein $(\mathrm{mg} / \mathrm{lung})$ & $8.78 \pm 0.51$ & $6.21 \pm 0.26^{*}$ & $7.61 \pm 0.52$ \\
& $(6)$ & $(6)$ & $(6)$ \\
DNA $\mu \mathrm{g} / \mathrm{mg}$ & $24.88 \pm 1.12$ & $27.24 \pm 1.83$ & $28.55 \pm 1.01$ \\
dry lung wt & $(6)$ & $(6)$ & $(6)$ \\
Protein mg/mg & $0.48 \pm 0.02$ & $0.52 \pm 0.02$ & $0.49 \pm 0.01$ \\
dry lung wt & $(6)$ & $(6)$ & $(6)$ \\
\hline
\end{tabular}

* Significantly different from control and pair-fed.

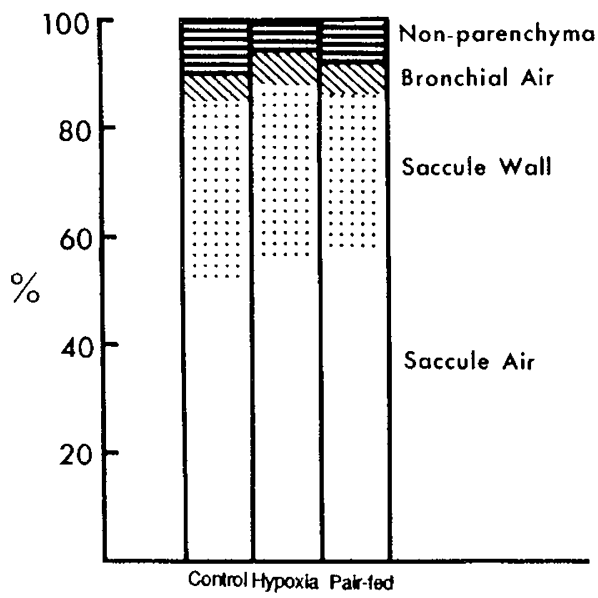

Fig. 1. Volume proportions of lungs as determined by point counting.

Table 1. Lung volumes, wt, and body wt ratios (mean $\pm S E M)^{*}$

\begin{tabular}{|c|c|c|c|}
\hline & $\begin{array}{c}\text { Control } \\
(n)\end{array}$ & $\begin{array}{l}\text { Hypoxic } \\
(n)\end{array}$ & $\begin{array}{l}\text { Pair-fed } \\
\quad(n)\end{array}$ \\
\hline Fetal wt $(\mathrm{g})$ & $\begin{array}{c}3.987 \pm 0.048 \\
(30)\end{array}$ & $\begin{array}{c}2.634 \pm 0.075 \dagger \\
(28)\end{array}$ & $\begin{array}{c}3.207 \pm 0.078+t \\
(33)\end{array}$ \\
\hline Dried lung wt (g) & $\begin{array}{c}0.0188 \pm 0.0008 \\
(30)\end{array}$ & $\begin{array}{c}0.0122 \pm 0.0009 \dagger \\
(28)\end{array}$ & $0.0153 \pm 0.0005 \dagger \neq$ \\
\hline Lung volume $(\mathrm{ml})$ & $\begin{array}{c}0.245 \pm 0.015 \\
(15)\end{array}$ & $\begin{array}{c}0.171 \pm 0.011 \dagger \\
(19)\end{array}$ & $0.198 \pm 0.009 \dagger$ \\
\hline Lung wt/body wt $(\mathrm{g} / \mathrm{g})$ & $\begin{array}{c}0.0046 \pm 0.0001 \\
(30)\end{array}$ & $\begin{array}{c}0.0047 \pm 0.0001 \\
(28)\end{array}$ & $\begin{array}{c}0.0048 \pm 0.0001 \\
(33)\end{array}$ \\
\hline Lung vol/body wt $(\mathrm{ml} / \mathrm{g})$ & $\begin{array}{c}0.0598 \pm 0.004 \\
(15)\end{array}$ & $\begin{array}{c}0.0595 \pm 0.003 \\
(19)\end{array}$ & $\begin{array}{c}0.0618 \pm 0.003 \\
(18)\end{array}$ \\
\hline
\end{tabular}

* Number in experimental groups vary. Lung volume measured on fixed lungs with evidence of proper inflation and weights measured on lungs used for biochemistry.

$\dagger$ Significantly different from hypoxic.

$\ddagger$ Significantly different from control. 
Table 3. Morphometric data of lungs (mean \pm SEM)

\begin{tabular}{lccc}
\hline & $\begin{array}{c}\text { Control } \\
(n)\end{array}$ & $\begin{array}{c}\text { Hypoxic } \\
(n)\end{array}$ & $\begin{array}{c}\text { Pair-fed } \\
(n)\end{array}$ \\
\hline Mean linear inter- & $56.08 \pm 2.01$ & $53.26 \pm 2.39$ & $52.06 \pm 1.70$ \\
cept $(\mu \mathrm{m})$ & $(10)$ & $(10)$ & $(10)$ \\
Surface area $\left(\mathrm{m}^{2}\right) \times$ & $0.838 \pm 0.045$ & $0.686 \pm 0.080$ & $0.812 \pm 0.066$ \\
$10^{-2}$ & $(10)$ & $(10)$ & $(10)$ \\
Surface area $/$ vol- & $0.073 \pm 0.008$ & $0.068 \pm 0.003$ & $0.077 \pm 0.009$ \\
ume $\left(\mathrm{m}^{2} / \mathrm{m}^{3}\right)$ & $(10)$ & $(10)$ & $(10)$ \\
\hline
\end{tabular}

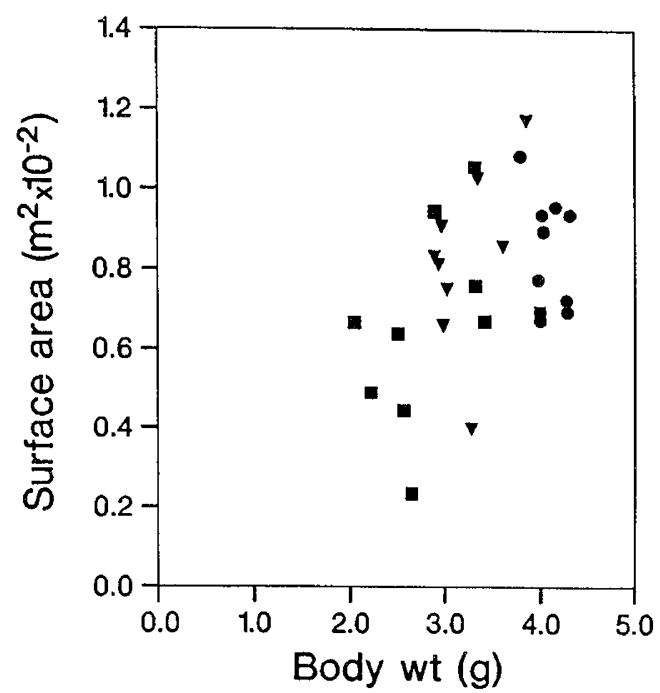

Fig. 2. Gas exchanging surface area relative to body weight. Solid squares, pups of hypoxic mothers; inverted solid triangles, pups of pairfed mothers; and solid circles, pups of control mothers.

believe that the decrease in lung weight is due to a decrease in total cell number. This is demonstrated by the significantly lower amounts of DNA in the hypoxic fetal lungs and by the similarity of relative amounts (weight DNA/dry lung weight) between the three groups.

Lung growth parameters such as weight and volume were proportional to the size of the fetus in each of the three groups. Morphometric indications of lung structure, such as volume proportion of lung components and the ratio of gas-exchanging surface area to lung volume and body weight, were also similar between groups.

These proportional reductions in growth have been found in previous studies of maternal exposure to chronic hypoxia and also in the study of maternal starvation. There was no change in the lung weight to body weight ratio in rabbits exposed for the last trimester at 55 torr of hypobaria (2). There was also no change in the lung weight to body weight ratio in fetal rats after maternal exposure to $13 \%$ ambient oxygen from day 3 to 20 of gestation (3). Acute prenatal starvation of guinea pigs (intake decreased by $50 \%$ ) showed proportional reductions in growth (19). Food intake in our hypoxic and pair-fed mothers was $48 \%$ of the control mothers.

Wigglesworth (6) has ligated the uterine artery in rats and showed no difference in the actual lung development between the smaller and larger fetuses. Our morphometric and morphologic analysis agrees with these findings. We did not find the developmental difference in lung noted by Lechner (19). He found that the smaller growth retarded fetuses within a litter of starved guinea pigs showed delayed maturation (saccular versus alveolar development), and that development would vary within a litter. Any other differences between groups (such as differences in gas-exchanging surface area) were due primarily to the difference in lung volumes between groups. Lechner found no difference between groups of the surface area to body weight ratio.
We found no significant differences in the mean linear intercept (an assessment of airspace size), surface to volume ratio (a better measurement of airspace size), and the gas-exchanging surface area between groups. The lungs of the hypoxic fetuses weighed less than their pair-fed and control cohorts, their lung volume was smaller but not significantly different from the pairfed lung volumes. Hypoxia may have some effect on the distensibility of lungs during inflation. The amount of fixative/wet lung weight was $0.63 \pm 0.01,0.75 \pm 0.01$, and $0.66 \pm 0.01 \mathrm{ml} / \mathrm{g}$ in the control, hypoxic, and pair-fed groups, respectively. A larger amount of fixative in the hypoxic lungs could account for the lack of significant difference in lung volume between the pairfed and the hypoxic groups. This increased distensibility would not only affect absolute lung volumes, but also mean linear intercept (that will change to the cube root of the lung volume changes) and surface area (that will change to the two-thirds power of the change in lung volume). Correction for a difference in distension from these data gives a mean lung volume of 0.144 $\mathrm{ml}$, mean surface area to volume ratio of $0.61 \mathrm{~m}^{2} / \mathrm{m}^{3}$, and a mean linear intercept of $50.06 \mathrm{~mm}$ in the hypoxic animals. However, it is probably better to regard the differences in distensibility as being a true function of lung structure rather than that we have underestimated the morphometric changes in the lungs of the hypoxic animals.

Our findings suggest that hypoxia in this experimental model only affects the lung as mediated by a decrease in total cell number which is symmetrical to the size of the fetus. It has been shown that intrauterine exposure to hypoxia can cause a decrease in fetal breathing (20) and that fetal breathing is a major determinant of lung growth (21). These studies have primarily been done on a short-term basis, however, and little is known about the effects of chronic hypoxia on fetal breathing. It could be possible that chronic hypoxia has very few effects mediated by a change in fetal breathing.

Our results were affected by the amount and duration of hypoxia that we chose to use. Exposure of hypoxia early in gestation has been shown to cause failure of implantation, resorption, and stillborns $(1,22)$ and exposure to less than $9 \%$ ambient oxygen has caused spontaneous abortions (5). This did not occur with our method of exposure. We noted a heart beat and spontaneous movements in our fetuses at time of cesarean section.

One of us has discussed at length elsewhere the concept of altered intrauterine lung growth (23) and has pointed out that hypoplasia, tissue maturity, cellular maturity, and tissue complexity may proceed separately. Hypoplasia is defined in Dorland's medical dictionary as "incomplete development or undevelopment" (24). The offspring of hypoxic mothers had lungs that were too small, in terms of volume, weight, protein, and DNA compared to the offspring of mothers fed ad libitum and this may be regarded as hypoplasia. However, all weights and volumes relative to body weight were the same in the three groups. Thus the effect was mediated primarily by fetal growth retardation. The diminished amount of DNA in the lungs of offspring of hypoxic mothers indicates too few cells, although $\mathrm{DNA} / \mathrm{mg}$ of lung was normal. Inasmuch as hyperplasia implies an increased number of cells, the lungs may be regarded as hypoplastic, although we believe this is arguable. Certainly, tissue maturity (apparent gestational age) and surface complexity (surface to volume ratio) were normal. Cellular maturity (surfactant content or number of osmiophilic lamellar bodies in alveolar type II cells) was not assessed in this study.

\section{REFERENCES}

1. Astrup P, Trolle D, Olsen HM, Kjeldsen K 1975 Moderate hypoxia exposure and fetal development. Arch Environ Health 30:15-16

2. Chang JHT, Rutledge JC, Stoops D, Abbe R 1984 Hypobaric hypoxia-induced intrauterine growth retardation. Biol Neonate 46:10-13

3. Garvey DJ, Longo LD 1978 Chronic low level maternal carbon monoxide exposure and fetal growth and development. Biol Repro 19:8-14 
4. Gilbert RD, Cummings LA, Juchau MR, Longo LD 1979 Placental diffusing capacity and fetal development in exercising or hypoxic guinea pigs. $J$ Appl Physiol 46:828-834

5. Van Geijn HP, Kaylor WM, Nicola KR, Zuspan FP 1980 Induction of severe intrauterine growth retardation in the Sprague-Dawley rat. Am J Obstet Gynecol 137:43-47

6. Wigglesworth JS 1964 Experimental growth retardation in the foetal rat. J Pathol Bacteriol 88:1-13

7. Lichty JA, Ting RY, Bruns PD, Dyar E 1957 Studies of babies born at high altitude. I. Relation of altitude to birth weight. Am J Dis Child 93:666-669

8. McCullough RE, Reeves JT, Liljegren RL 1977 Fetal growth retardation and increased infant mortality at high altitude. Arch Environ Health 32:36-39

9. Karnofsky MJ 1965 A formaldehyde-glutaraldehyde fixative of high osmolality for use in electron microscopy. J Cell Biol 27:137-138(abstr)

10. Scherle W 1970 A simple method for volumetry of lungs in quantitative stereology. Microskopie 26:57-60

11. Dunhill MS 1962 Quantitative methods in the study of pulmonary pathology. Thorax 17:320-328

12. Schmidt G, Thannhauser SJ 1945 A method for the determination of desoxyribonucleic acid, ribonucleic acid, and phosphoproteins in animal tissues. $\mathbf{J}$ Biol Chem 161:83-89

13. Wannemacher RW, Banks WL, Wunner WH 1965 Use of a single tissue extract to determine cellular protein and nucleic acid concentrations and rate of amino acid incorporation. Anal Biochem 11:320-326

14. Burton K 1956 A study of the conditions and mechanisms of the diphenyl- amine reaction for the colorimetric estimation of deoxyribonucleic acid. Biochem J 62:315-323

15. Lowry OH, Rosebrough NJ, Farr AL, Randall RJ 1951 Protein measurement with the folin phenol reagent. J Biol Chem 193:265-275

16. Zar JH 1984 Biostatistical Analysis, 2nd ed. Prentice-Hall, Inc, Englewood Cliffs, NJ, pp 190-000

17. Langston C, Thurlbeck WM 1982 Lung growth and development in late gestation and early postnatal life. In: Rosenberg HS (ed) Perspectives in Pediatric Pathology. Year Book Medical Publishers, Chicago, pp 203-235

18. Burri PH 1984 Fetal and postnatal development of the lung. Annu Rev Physiol 46:617-628

19. Lechner AJ 1985 Perinatal age determines the severity of retarded lung development induced by starvation. Am Rev Respir Dis 131:638-643

20. Boddy K, Dawes GS, Fisher R, Pinter S, Robinson JS 1974 Foetal respiratory movements, electrocortical and cardiovascular responses to hypoxaemia and hypercapneia in sheep. J Physiol (Lond) 243:599-618

21. Wigglesworth JS, Desai R 1982 Is fetal respiratory function a major determinant of perinatal survival? Lancet 1:264-267

22. Rattner BA, Ramm GM 1975 Effects of hypoxia on early pregnancy and embryonic development in the mouse. Aviat Space Environ Med 46:911 915

23. Cooney TP, Thurlbeck WM 1985 Lung growth and development on anencephaly and hydranencephaly. Am Rev Respir Dis 132:598-601

24. Friel JP (ed) 1981 Dorland's Illustrated Medical Dictionary, 26th ed. WB Saunders, Philadelphia, pp 642-000 